Copyright (C) 2021 by Academic Publishing House Researcher s.r.o.

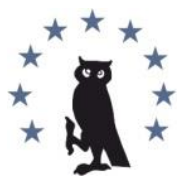

Published in the Slovak Republic

Media Education (Mediaobrazovanie)

Has been issued since 2005

ISSN 1994-4160

E-ISSN 2729-8132

2021. 17(3): 398-407

DOI: $10.13187 / \mathrm{me} .2021 .3 \cdot 398$

www.ejournal53.com

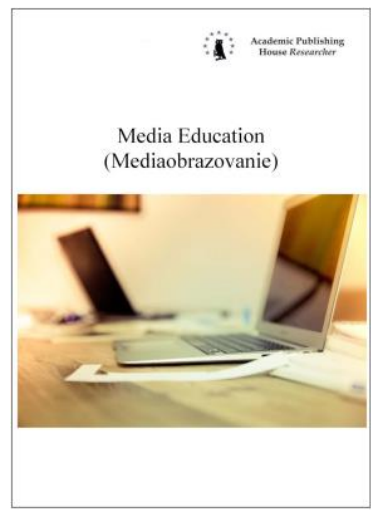

\title{
Social TV Advertising in Ukraine and the EU: Topics, Impact, Effectiveness through the Prism of Media Literacy
}

\author{
Oksana Bilous a, * \\ a Ivan Franko National University of Lviv, Ukraine
}

\begin{abstract}
Today, social advertising is one of the powerful means of influencing society. Civilized countries have long used the opportunities of this type of advertising to minimize or even eradicate the negative phenomena that exist in every country and do not have the best impact on the lives of citizens. Television advertising due to its mass has a significant impact on various segments of society. The article is devoted to the study and research of social advertising on television.

In this work there were studied concept of "social advertising" and its features, the specifics of social advertising on TV channels, the role of social advertising in the solving the problems of the population. It was analyzed social advertising in the EU, as well as formulated recommendations for improving social advertising in Ukraine. The topic of social advertising in Ukraine is also eradicated, examples of successful social advertising campaigns in Poland, Latvia and the Czech Republic are depicted. On this base Recommendations for improving social advertising and increasing its impact on the social media literacy of viewers are offered.
\end{abstract}

Keywords: social media literacy, advertising, TV, impact, audience.

\section{Introduction}

For the second century, social advertising as a technology of governance has accompanied the democratic development of the most successful states and has established itself as a quite successful institution. In the modern science of public administration, it is considered as one of the most important tools, which, forming appropriate psychological guidelines for citizens, creates the preconditions for the implementation of social policy of the state, increases the social media literacy of the population. With the exacerbation of medical problems in the world, namely the COVID-19 pandemic, there is an urgent need to strengthen social advertising and improve its quality. Considering advertising as a tool to influence the consciousness of the audience, it should be noted that this influence should always reflect a positive effect, as advertising is one of the means of mass consciousness, one of the methods of humanization of society aimed at improving and reviving moral values. The main role at this time is played by the media. On the one hand, the media reflect social phenomena, internal relations in the country, on the other hand, form public identity and behavioral patterns in society, thus being the main ideological tool.

In the second half of the 1990s, one of the means of forming a public position was social advertising, which appeared in newspapers and on television. Many researchers believe that the most effective social advertising is on television. This is mainly due to its specific properties the ability to act on several senses (sight and hearing) (McLean et al., 2017). We live in a society

\footnotetext{
${ }^{*}$ Corresponding author

E-mail addresses: bilousoksana950@gmail.com (O. Bilous)
} 
in which advertising plays a very important role. A feature of advertising in developed countries is the extreme prevalence of social advertising, which insistently promotes a healthy lifestyle, organized environmental protection, law-abiding behavior, as well as positive values and standards of public life. In Ukraine, the Law does not limit the range of entities that can be advertisers of social advertising and defines a number of significant preferences for the development of social advertising, namely: extension of benefits provided for charitable activities to persons who produce and distribute social advertising or transmit their property and funds for its production and distribution.

$5 \%$ quota of advertising space or airtime in state and municipal media for free social advertising of public authorities, local governments and NGOs; benefits for the placement of social advertising in state and municipal media by budgetary institutions of education, culture, health care, as well as charitable organizations (Rubtcova, Pavenkov, 2018). Social advertising can be an effective method for increasing the level of media literacy in society through refuting fakes and disinformation, providing truthful information and call for analysis of information which we get from different sources. But to accomplish this goal social advertising should meet the needs of audience, be interesting, effective and have a trust among viewers. That is why our researching is directed to the analysis of social advertising in Ukraine, it`s themes, creativeness, accordance to the needs of audience and impact of it.

\section{Materials and methods}

While working on this research, the method of systematic study and analysis of publications of authors and experts in the field of television social advertising was used. The next step in the study was to conduct a survey $(\mathrm{N}=568)$ for determining the role of scientific information for the audience, as well as to identify relevant methods of presenting scientific information. It was made a questionnaire and respondents could fill it via an Internet link in Google form. This link was sent by messengers and was also posted on the author's account in the social network Facebook. The questionnaire consisted of 7 questions - open and close types. The survey was anonymous and at the beginning of the survey there was information that the results of the survey will be used for scientific research and will be generalized. In general, 568 respondents passed the survey, among them - students, journalists, economists, teachers, psychologists etc. From the gender division 300 women and 268 men.

To analyze social advertising on television, the method of monitoring social advertising on TV channels ICTV, STB, New Channel, Channel 5, 1+1, Inter was used, as well as monitoring of social advertising on Polish television (Polsat, TVP 1, TVP 2), Czech (CT 1, CT 2), Latvian (LTV 1, LTV 7) and French (France 2) channels. Monitoring of foreign social advertising helped to compare Ukrainian social advertising with advertising in the European Union.

\section{Discussion}

Most European countries include media education in their formal education systems as a separate subject or as a part of other subjects with corresponding content. Media education is also a part of non-formal education in many countries (Petranova et al., 2017). One of the forms of nonformal education is social advertising. The audiovisual content can provide an effective forms media literacy (Camarero et al., 2019). S. Ljajić says that the media audience no longer acts passively and at the request of the media contentproducers, but creatively and inherently deciphers what the media offers it (Ljajić, 2021). So TV can be the source of useful content for viewers. One of the forms of such audiovisual content is social advertising (Tikhomirova et al., 2017). In the comparison with commercial advertising, the aim of social advertising is to help people in solving their problems, inform about possibilities and opportunities, anticipate diseases and treat them (Kitsa, Mudra, 2020).

The term "social advertising" is used only in the CIS countries. In the United States and Europe, the terms "public service advertising" or "public service announcement" (PSA) are used to refer to this type of advertising (Mingoia et al., 2019). Therefore, social advertising is usually defined as advertising that is dedicated to the public interest. The topics of such advertising are the impact on public opinion on health, social protection, human rights, environmental protection, crime prevention, public safety and other socially important issues (Manca et al., 2021). In the West, the term "social advertising" corresponds to the concepts of non-commercial and public advertising. Non-profit advertising involves advertising activities paid for by public non-profit 
institutions to encourage donations; calls to vote for someone or to provide public support; to draw attention to the problems of society, etc. (Sarwatay et al, 2021). Public advertising is aimed at promoting positive phenomena for society and, as a rule, is placed in the media free of charge. Countries with developed democracies clearly understand what social advertising is for and how it can be used in certain segments of the socio- political and economic life of society (Tandoc et al., 2021). For them, the purpose of such advertising is not empty talk and ideas, but a clear motivation for actions, the creation of new, socially useful values. With the help of social advertising, the state promotes services and reports on the performance of its social functions. CSOs draw the attention of citizens, government agencies and businesses to socially significant issues, form a positive public opinion (Tully et al., 2020). On our mind, social advertising can improve the level of media literacy among elder people, which, Rasi et al. say is important in modern media sphere (Rasi et al., 2021). In fact, it can help to separate the truth form false in different spheres, not only in social, but also in political, economic etc. (Hameleers, 2020). Moreover, R. Festl declares that media literacy, and social advertising as a mean of it, can influence also on the social online behavior (Festl, 2021). On our mind, in the era of disinformation, social advertising can be directed to the propaganda of healthy way of life, vaccination, especially during the COVID-19 pandemic etc. So it can prevent the negative influence of fake news on the one hand in new media, on the other - on TV (Cheng, Chen, 2020). Furthermore, it can lead to increasing new media literacy in the society (Tugtekin, Koc, 2020). But to achieve this result social advertising should be effective and be in trust in the society. It should depict actual demands of the society, be informative, truthful and evidentiary.

A. Boravska singles out the motives of social advertising which can be grouped into two major groups: emotional motives and moral reasons. The scientist declares that emotional motives in advertising "play" on the desire of recipients to get rid of negative and achieve positive emotions (Boravska et al., 2020). B. Casais and A.C. Pereira declare that to be effective in social advertising should prevail emotional and rational one (Casais, Pereira, 2021). The purpose, content and objectives determined the following functions of social advertising: informational, economic, educational, socio-regulatory, aesthetic, communicative, image (Göttlichová, 2019).

Thus, social advertising is an extremely important aspect in the development of a civilized democratic society and social media literacy. The functions of social advertising have an extremely important impact on the development of social media literacy (Buckingham, SeftonGreen, 2018). If social advertising performs its main functions, it can serve as a kind of cleansing filter of society from the negative factors that adversely affect the development of a country. This is also facilitated by maximum personalization (Dzhavadian, 2020). Studies repeatedly conducted by Western psychologists show that advertising which is often shown on television, automatically enters the subconscious of the viewer, prompting him to certain actions. The peculiarity of television social advertising is its individual direction, pronounced structure (introduction, main part and conclusions), color images (Koszembar-Wiklik, 2018).

G. Isanova declares that social advertising has the following main features and characteristics: the viewer remembers visual information rather than audio; use of visual images, bright details; graphic information; personification (the role of experts is often played by celebrities - actors, athletes, politicians, evoke a certain degree of trust in the domestic television audience); brevity, clarity and purposefulness of social information; always in the center is a man as the main subject, the timeliness of factual and scientific information, the opinion of experts (Isanova, 2017). Today, social advertising is an important tool for forming public self-awareness, constructing a public position and a means of communication between society and the state. It is worth noting that social advertising is two-way. Both society and the state depend on how effective and strong the social relationship will be and how quickly behavioral attitudes and models will be formed in society (Bulanda et al., 2020). With the help of social advertising you can solve many problems: complex relationships between parents and children, ethnic hatred, drug addiction, alcoholism (Brusenskaya, Kulikova, 2019). Due to our previous researches, the depicting of these themes in social advertising depends of the level of spreading of such problems in the society, and in different countries this level can be other. While speaking about the themes and causes of social advertising, it is worth noticing that it can increase the level of media literacy of viewers while debunking fakes and disinformation (McDougall, 2019). But on our mind, to reach the goal in refuting fakes social advertising should at first be in trust among society, have an impact on the audience and be effective. 


\section{Results}

It seems that today it makes no sense to ask whether society needs social advertising, because in all civilized countries of the world the model of social advertising is actively used to improve the behavior of its citizens, to form a positive attitude to current issues. According to our research, in Ukraine only a little more than half of the population (54 \%) believe that social advertising is necessary, the other half is approximately equally represented by opponents of social advertising and those who have not yet decided on their attitude to it. This skepticism is explained by the fact that not all citizens distinguish between the concepts of social and commercial advertising. By type of social advertising has the greatest impact on the actions of respondents. Most often, Ukrainians mentioned commercials shown on television (42\%), in second place - social television programs (19 \%), journalists' reports (16\%), also influenced by external media, social campaigns, social articles and in the press, etc., but much to a lesser extent. Most of our respondents are much more exposed to social advertising ( $44 \%$ women, $30 \%$ men). Residents of the western regions are more likely to notice the impact of social advertising than residents of the center or southeast. Emotional influence from it is seldom recognized by residents of the capital (31\%), more often - by residents of cities (39\%) and most often by villagers (42\%).

As far as adult Ukrainians believe in social advertising, we can say that only $8 \%$ of people change their behavior for the better under the influence of social advertising, $38 \%$ of Ukrainians think about the problems it raises, $29 \%$ of respondents do not affect it at all, another $12 \%$ of our citizens cause a negative attitude. Thus, social advertising on television has its own specific features, it is a powerful factor that can change the vector of social development. In practice, there are many specific types of social advertising on television, which can be combined into the following types of social advertising:

1. Social advertising of a healthy lifestyle, which includes the promotion of life without smoking, alcohol abuse, drugs and psychotropic substances, promotion of sports lifestyle.

2. Social health advertising which includes prevention of smoking, prevention of alcoholism and alcohol abuse, prevention of drug addiction, prevention of AIDS and sexually transmitted diseases (STDs). In 2020-2021, such advertising also covers the topics of coronavirus, in particular how to protect yourself from it, as well as why vaccination is needed.

3 . Social advertising of nature protection and conservation of energy resources.

4. Social advertising of law and obedience to the population as a model of behavior, where there is informing the public about existing political, economic, cultural, social and other rights, guarantees and opportunities, promotion of civil dignity, crime prevention, social protection and security.

5. Advertising of social services and other similar institutions includes advertising of the institutions themselves, as well as advertising of services provided by the institution (informing the population).

There is a small amount of quality social advertising on Ukrainian television. Our country is at the stage of formation and rapid development of the media industry. Ukrainian society is just beginning to realize that social advertising is an important component of the advertising market. If you ask the average Ukrainian about social advertising on domestic television, you can immediately hear about a series of commercials on the fight against AIDS. O. Pinchuk's Anti-AIDS Foundation became the creator of this advertisement. This is the first charitable organization in Ukraine aimed at combating the AIDS epidemic, which works at the expense of private funds. These commercials were broadcasted on ICTV, STB, New Channel. To understand what this ad is, you should analyze a few videos. In one such video, we see a young girl who feels happy with a new lover. But all the joy dissipates when the young lady goes to the kitchen and sees other girls living in the apartment.

The video series is accompanied by appropriate musical design, which should encourage young people to think about their sex life. An anxious voice-over says, "You can trust your partner, but you can't be sure of all his previous partners." Another video of the Anti-AIDS Foundation shows the viewer the chain of chaotic sexual life of young people, as well as the problem of drug addiction among the population. In the frame, we can see a young girl infected with the virus, from which everyone turns away and is afraid. A voice-over says, "You choose who to talk to, AIDS doesn't. AIDS is closer than you think". Another original video shows us how a cute blonde woman is going on a date and how a chubby soldier is preparing for important trainings. The authors of the video tried to convey to the viewer that contraception is already important for modern 
youth. But in addition to AIDS, there are many other important issues in modern society that need to be addressed. Social advertising is one of the components that can reduce the negative trends in the population of the country and improve the level of media literacy.

As it was mentioned above, the study of the consumer's opinion of a social advertising product was provided with the help of an anonymous questionnaire. It is this method of gathering information that outlined a clear picture of the state of television social advertising on Ukrainian television, showed the attitude of Ukrainian citizens to social problems. It will be expedient to evaluate the results of the research with the help of diagrams that show the percentage in the answers of the respondents. The survey showed that $39 \%$ of Ukrainians don 't watch television. $28 \%$ view social advertising only if it is interesting and meaningful. $25 \%$ of respondents watch all the content of social advertising presented on television. The amount of respondents who do not watch advertising at all is $8 \%$.

\section{Do you watch social advertising on TV?}

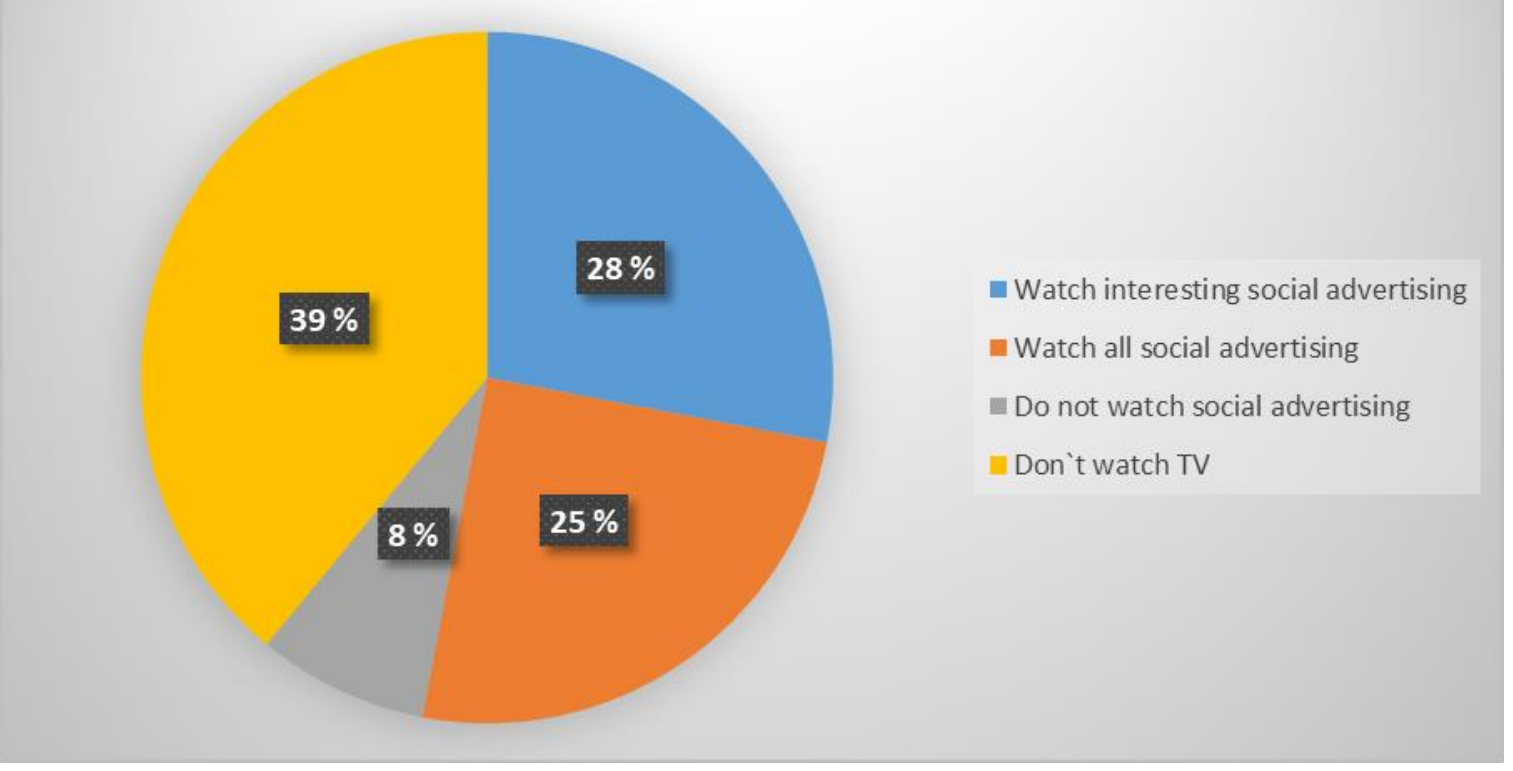

Fig. 1. Do you watch social advertising on TV?

It should be noted that people who do not watch television watch social advertising on the Internet. Therefore, it can be assumed that social advertising is an area of interest to Ukrainian society. Recognition of social advertising is an important factor in its effectiveness. Most respondents were able to recall social videos on the fight against HIV/AIDS (45 \%). In second place - social advertising about the Ukrainian army (33 \%). Ukrainians remember the least about advertising on the dangers of drugs, alcohol and smoking (22 \%). Also $50 \%$ of recipients find it difficult to choose the priority issues that should be covered by social advertising. $25 \%$ believe that the environment, social support for vulnerable groups, the decline in the prestige of vocational education, youth issues are key to social advertising in Ukraine. Abortions, overcoming the demographic crisis, the fight against poverty and unemployment are identified by $17 \%$ of respondents. Only $8 \%$ consider drug addiction, bad habits and the spread of HIV/AIDS to be the most important problems.

These results lead to the conclusion that Ukrainian society has other demands on the subject of social advertising. There is a need to diversify the themes of social videos. Terrible social advertising causes a lot of discussion among viewers. $50 \%$ of respondents said that they would like to see such advertising on Ukrainian television, but in limited quantities. $25 \%$ believe that it can be broadcast on Ukrainian TV without fear. Terrible social advertising has no place on Ukrainian television - this is the opinion of another $25 \%$ of respondents.

Ecology, social support of vulnerable groups, problems of young abortions, overcoming the demographic crisis, combating poverty and unemployment drug addiction, bad habits, the spread of AIDS/AIDS are the themes which half of our respondents would like to see in 
advertising. Ukrainians do not trust all social advertising. $50 \%$ of respondents said that they trust only some videos and are guided in choosing their own feelings, intuition. $20 \%$ of respondents expressed distrust in Ukrainian social advertising. 22 \% said they trust social advertising. The participants of the survey wrote that they did not know how to treat social advertising and pointed out the contradiction of their impressions of the Ukrainian social worker (9\%).

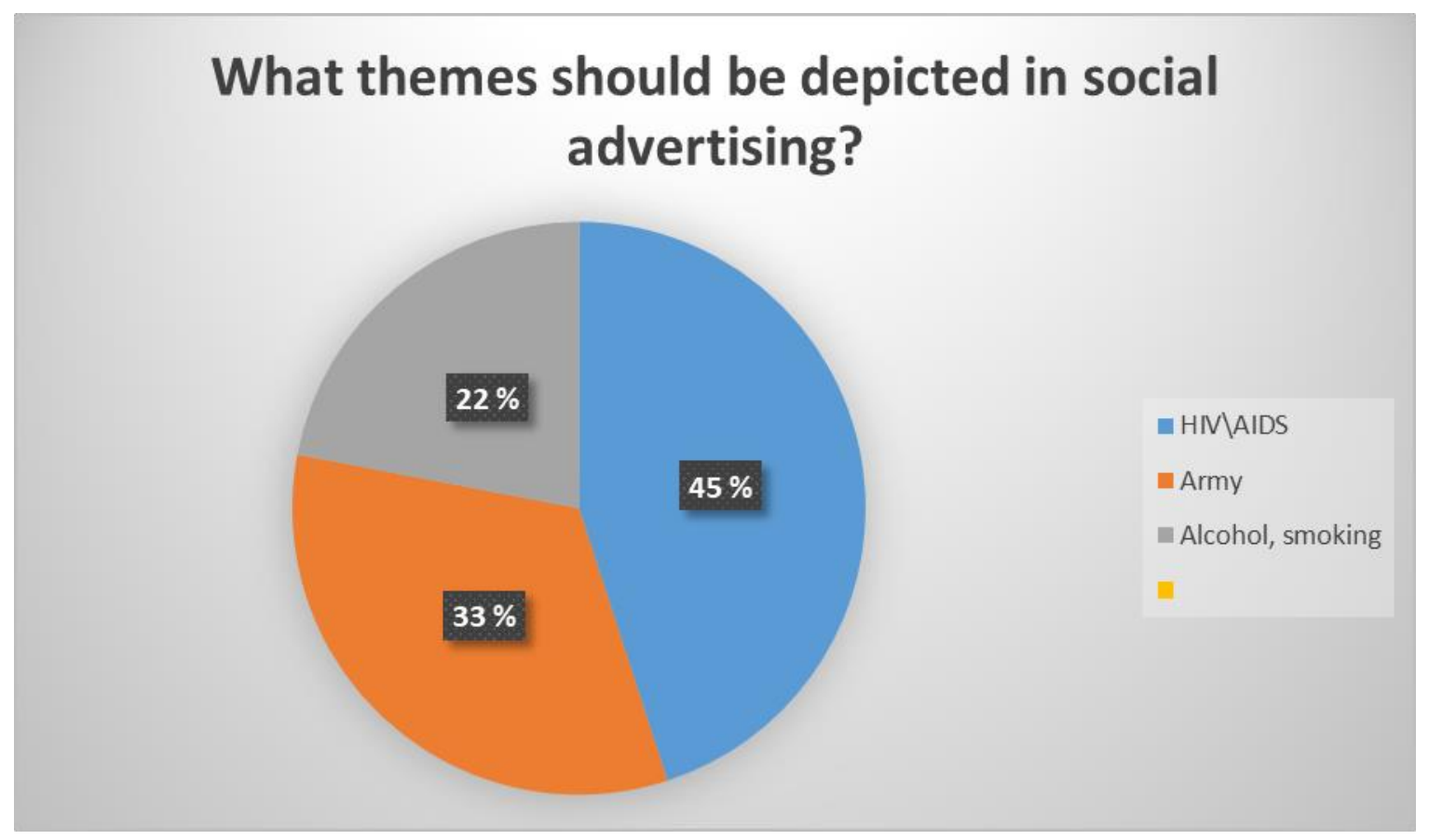

Fig. 2. What themes should be depicted in social advertising?

Social advertising aims to solve important social problems and have a positive impact on the population, though $40 \%$ of respondents believe that television social advertising is not able to solve problems in Ukraine. Social advertising "cures" society - 29 \% of respondents think so. 20 \% tend to believe that social advertising solves social problems only in economically developed countries. Respondents also said that social advertising gives a boost and makes you think. Some believe that it does not solve anything, but only raises important issues (11\%). It is worth noting that $29 \%$ of respondents believe that the effectiveness of social advertising is influenced by the appearance in the frame of celebrities (actors, athletes, politicians). The issue of building civil society is relevant for Ukraine. $40 \%$ of respondents believe that social advertising is an important factor in shaping civil society. Respondents expressed the view that social advertising cannot bring significant changes, but it is an integral attribute of civil society. Respondents believe that Ukrainian television lacks the most social advertising about environmental protection, advertising about domestic violence, the problems of various forms of discrimination and the importance of quality education. Respondents are concerned about the problems of ecology and animal protection. After all, this is the kind of advertising they most want to see on Ukrainian television (38\%).

Moreover, $20 \%$ of our respondents want to see more advertising about the dangers of drugs, alcohol and smoking. $15 \%$ of respondents are concerned about discrimination based on sex, religion or religion. $6 \%$ of respondents would like to see advertisements for domestic violence. $21 \%$ of respondents suggested their options. Ukrainians would like to see advertising that raises the question of the role of each individual in the formation of the state and advertising about patriotism. So, when developing social advertising, it is worth thinking about what actions we want to achieve from the representative of our target audience, what behavior we seek to form. It is important to remember that people act only to meet their own needs, which are different. Knowing the target audience, it is necessary to appeal to those of its needs that are most relevant to it, and show the target audience what they should do or how to change their behavior in order to meet these needs.

In order to explore the topic of social advertising more comprehensively, we conducted a review of social advertising abroad. Poland is a country that, like Ukraine, left the Soviet Union 
more than 25 years ago, but in the field of media and social advertising is well ahead of our country. In Poland, social advertising is now very popular. It is devoted to a wide range of issues. These are campaigns against drunk driving (it involved real victims of accidents who became disabled); about the inattention of pedestrians on the roads (shocking outdoor advertising with corpses under the sheets); a whole series of medical campaigns (against hepatitis). Monitoring of Polish television has shown that channels do not show social videos very often. But the subject of Polish television social advertising is quite extensive. Attention draws a series of short videos, Oh czekiwania vs. Rzeczywistość (Expectations vs Reality). This is a nationwide campaign created with the support of the General Sanitary Inspectorate of Poland. Each video in this series is dedicated to a certain bad habit. The authors show the viewer two options. The person who uses certain substances feels energetic and joyful - this is shown in the first part of the video. The unpleasant and insignificant reality is shown by the second part of these in the video. Let's look at each video in more detail. The video about the dangers of smoking Fajki - Oh czekiwania vs. Rzeczywisto ść (Cigarettes Waiting vs. Reality) tells the story of a young girl who smokes a cigarette and feels fashionable and stylish at a party. Cigarettes give her confidence. The young lady notices a guy who smiles at her. But when the young man comes closer, he feels the unpleasant smell of cigarettes. He walks away, and the girl is left alone. This is its reality.

Another video Wódka-Oczekiwania vs. Rzeczywisto ść(Vodka - Expectation Vs Reality) paints a picture where a guy gets drunk at a party. Alcohol makes him a daredevil and a king of dances, but in reality he can barely get over his feet and vomit because he has drunk too much. A reality that can warn someone against an extra glass. Marijuana smoking is horrible reality shows video Zioło Oczekiwania vs. Rzeczywisto ść (Grass - Expectation Vs Reality). According to the plot, three girls are going to a pajama party. To diversify their leisure time, young ladies decide to smoke herbs. The result: inadequate and strange people lying in different corners of the room. To get an unforgettable experience, modern youth resort to the use of hallucinogenic mushrooms. The way it looks really shows the video Grzyby - Oczekiwania vs. Rzeczywisto ść (Mushrooms - Expectations vs. Reality). The boy and the girl take mushrooms and it seems to them that they are the heroes of a fantasy film about unearthly love, but in reality young people are lying on the floor in public transport and their inappropriate behavior attracts the surprised eyes of passengers.

All videos in this series were shot with high quality and in a youthful style. The authors use popular music that attracts the viewer's attention. The creators of Polish social advertising like to use scary stories. Such advertising is quickly remembered and lives in the human mind for a long time. A few years ago, a video about animal protection Pies to nie zabawka (Dog is not a toy) was popular in Poland. According to the plot, the family gathers at the festive Christmas table. Everyone is having fun and greeting each other. Parents decide to give their little son a puppy. At first, the boy is happy with the gift and plays with the dog. But then the pet bores the little ones. The father of the family approaches the animal and shoots it with a pistol. The finale is frightening and makes you think. The video ends with the words: Don't be a cat. A dog is not a toy.

In the Czech Republic, the creators of social advertising pay much attention to the topic of careful driving. A series of short videos Niemyslis - Zaplatis (You do not think - pay) in a terrible form tells the stories of people who were injured in car accidents in various circumstances. Czech social advertising tells about the everyday life of Ukrainian workers. Human rights activists in the country have decided that the Czech population humiliates Ukrainian women who come there to work. In a video on the subject, a man scolds a governess for touching his papers on his desk while cleaning. A man cannot find a completed math task. Then the woman takes the pen and solves the problem herself. Then it turns out that before coming to the Czech Republic, she worked for eight years as a math teacher in high school. The video ends with the words: Do you know who cleans your house?

Social advertising in Latvia often covers safety issues behind the wheel. In one of the videos, a young man says that his head can do many things. He thinks, eats, laughs, kisses, lives. The guy claims that his head can do anything, even kill. The voice-over explains that during an accident, a person's head turns into a solid stone. If you do not fasten your seat belts, you can break the head of the person sitting in front. That is why it is important to use seat belts, even if you are in the back seat. After analyzing social advertising in the four countries of the European Union, we can conclude that Europeans pay a lot of attention to animal protection, the fight against drug addiction, alcoholism, smoking, car accident prevention and discrimination. Comparison of Ukrainian and foreign social advertising is very relevant today. The method of comparison and 
analysis aims to identify the shortcomings of Ukrainian television social advertising and make a list of actions that can improve it. The main disadvantage of social advertising in Ukraine is its insufficient thematic diversity. The topic of migrants is also relevant in EU countries.

The UK, which has begun the process of leaving the EU, continues to shoot social videos in support of Syrian refugees. The British Charity Save the Children shot a video that turned London into Syria in a minute and a half. According to the plot, a little girl in London celebrates her birthday. She lives like most children in the city: plays with a dog, draws, goes to school, rides on a carousel. The first part of the video is very nice and enjoyable. But then something explodes, sand begins to fall from the ceiling, war begins. And the rhythm of a child's life changes. This is the same London, but it is being shot and killed. The advertisement shows the terrible changes that come to the lives of young children with the war.

If we compare the coverage of the topic of environmental protection in social advertising, the situation in Ukraine and the European Union has significant differences. In Ukraine, the problem of garbage pollution has become one of the key. The approach to its solution is different. This is demonstrated by the social video Garbage. In the video we see a man. He walks through the picturesque landscapes of the Carpathians and photographs interesting landscapes. On his way, the photographer sees a lot of garbage that people leave behind. Garbage does not get into the lens of his camera, but he decides to collect it. The protagonist of the video says: Who are the people who leave garbage wherever they come? I stopped asking myself these questions. I just clean up the garbage that lies in my way. Everyone can do it. The video concludes with the text: Start collecting garbage wherever you go. You can pick up garbage from beautiful places, but then it will most likely end up in one of the landfills in our country, which according to the Ministry of Environment is $7 \%$ of the total area. Polish social advertising on this topic offers another solution to the problem. In the video Zadbaj i nie ptać (Take care and don't pay) we see a man, he dumps all the garbage in one tank. It is approached by a woman who sorts it into three containers: Plastic, Paper, Glass. Thus, the Polish government encourages citizens to sort household waste, as it is an important point of the environmental campaign. The video ends with the text $I$ sort and it costs me nothing.

Speaking about the effectiveness of social advertising in EU, we should notice that it is much higher than in Ukraine. According to the research of our colleagues, social advertising pay attention to the existence of the problem (48.8\%) and tend to thoughts presented the problem (36.9\%). Only a small percentage of respondents selected the answer that tend to change attitudes and behavior (3.6 \%) (Szwajca, 2015). If the audience think that social advertising pay attention to the problem, this is an indicator that it is effective, because the main goal of this kind of advertising is to show the problem and help in it s solving. So in this case we can examine social advertising through the prism of media literacy, while as such advertising have an impact and trust among viewers, it can be used to refute fakes, change the thought of society about some problems and its solving, promote different social changes etc. In EU social advertising can be used as an effective tool of fighting against disinformation, because, according to the previous researching (Szwajca, 2015), it has a high level of the interest (in general - 93\%) and impact (near $80 \%$ ) in the society, while in Ukraine this indicator is too low (40 \% and $28 \%$ ).

\section{Conclusion}

To promote media literacy in the society and to refute disinformation, social advertising should have a positive impact on the audience, be effective and have a trust in society. Our researching has shown that social advertising in Ukraine does not have such indicators yet. Thus, Ukrainian social advertising has a number of shortcomings and is inferior to foreign. It is worth noting that recently television advertising on Ukrainian television is not enough. Channels from other countries broadcast it in greater numbers, social videos in the EU have a more thematic diversity and a completely different approach to covering issues. On the base of our researching we can propose such recommendations for improving the quality of television social advertising and making it more effective: diversification of social advertising; the use of vivid images in social advertising; promotion of high moral values in social television advertising; involvement of talented and professional people in the creation of television social advertising; study of public opinion on improving social advertising, establishing a dialogue between the population and organizations that create social advertising, control of the content and quality of social advertising by active citizens. 
Analysis and comparison of social advertising on Ukrainian television with social advertising in the European Union helped to find constructive solutions to solve the problems of Ukrainian society in this area. To earn trust in the society the issue of broadcasting social advertising and quality control should become one of the key tasks of public policy in the near future. TV channel owners need to feel responsible for their viewers. It is then that high-quality social advertising will be broadcast on Ukrainian channels in accordance with the law and be more effective. Only in this case social advertising will become a mean of increasing media literacy among it's audience.

As we had examined, in Ukraine social advertising is much less effective, than in EU. The main reason of this is that social advertising in Ukraine is less creative and not represent the themes and problems, which are the most actual for our citizens.

Considering advertising as a tool to influence the consciousness of the audience, it should be noted that this influence should always reflect a positive effect, as advertising is one of the means of mass consciousness, one of the methods of humanization of society aimed at improving and reviving moral values. It should be borne in mind that society needs to "recover", solve social problems, raise important social issues at the general state level.

In a global context while increasing the effectiveness and the trust of people to social advertising, it can become an important mean for decreasing and refutation of fakes in media and increasing the level of media literacy in the society.

\section{References}

Borawska et al., 2020 - Borawska, A., Oleksy, T., Maison, D. (2020). Do negative emotions in social advertising really work? Confrontation of classic vs. EEG reaction toward advertising that promotes safe driving. PLoS one. 15(5).

Buckingham, Sefton-Green, 2018 - Buckingham, D., Sefton-Green, J. (2018). Multimedia education: Media literacy in the age of digital culture. In Media literacy in the information age. Routledge: 285-305.

Bulanda et al., 2020 - Bulanda, I., Kádeková, Z., Košičiarová, I., Vavrečka, V. (2020). The Perception of commercial and social advertising by the generation $\mathrm{Y}$ in the Czech Republic. Ekonomicko-manazerske spectrum. 14(2): 63-77.

Camarero et al., 2019 - Camarero, E., Fedorov, A., Levitskaya, A. (2019). Audiovisual and media literacy for social change. In The Routledge Handbook of Positive Communication: 356-363. Routledge.

Casais, Pereira, 2021 - Casais, B., Pereira, A.C. (2021). The prevalence of emotional and rational tone in social advertising appeals. RAUSP Management Journal. DOI: https://doi.org/ 10.1108/RAUSP-08-2020-0187

Cheng, Chen, 2020 - Cheng, Y., Chen, Z.F. (2020). The influence of presumed fake news influence: examining public support for corporate corrective response, media literacy interventions, and governmental regulation. Mass Communication and Society. 23(5): 705-729.

Dzhavadian, 2020 - Dzhavadian, O.M. (2020). The impact of social advertising on mental health of population. Mental Health: Global Challenges Journal. 3(2): 4-5.

Festl, 2021 - Festl, R. (2021). Social media literacy \& adolescent social online behavior in Germany. Journal of Children and Media. 15(2): 249-271.

Göttlichová, 2019 - Göttlichová, $M$. (2019). Social advertising as a socialization factor of the contemporary youth. West East Journal of Social Sciences. 8(1): 93-108.

Hameleers, 2020 - Hameleers, $M$. (2020). Separating truth from lies: Comparing the effects of news media literacy interventions and fact-checkers in response to political misinformation in the US and Netherlands. Information, Communication \& Society: 1-17. DOI: 10.1080/ 1369118X.2020.1764603.

Isanova, 2017 - Isanova, G. (2017). Social advertising: its understanding and role in public consciousness. ISJ Theoretical \& Applied Science. 3(47): 59-62.

Kitsa, Mudra, 2020 - Kitsa, M., Mudra, I. (2020) Gender stereotypes of women in television advertising in Ukraine, Feminist Media Studies. 20(3): 381-397.

Koszembar-Wiklik, 2018 - Koszembar-Wiklik, M. (2018). Social advertising as a mirror image of social issues. Marketing Identity. 6(1/1): 360-369. 
Kulikova, Brusenskaya, 2019 - Kulikova, E.G., Brusenskaya, L.A. (2019). Social anti-drug advertising in the modern media as a factor of national security. Media Education. 59(2): 286-295. DOI: $10.13187 / \mathrm{me} .2019 .2 .286$.

Ljajić , 2021 - Ljajić, S. (2021). Media, ethical norms and media literacy education. Facta Universitatis, Series: Teaching, Learning and Teacher Education: 185-194.

Manca et al., 2021 - Manca, S., Bocconi, S., Gleason, B. (2021). Think globally, act locally: A glocal approach to the development of social media literacy. Computers \& Education. 160.

McDougall, 2019 - McDougall, J. (2019). Media literacy versus fake news: critical thinking, resilience and civic engagement. Media Studies. 10(19): 29-45.

McLean et al., 2017 - McLean, S.A., Wertheim, E.H., Masters, J., Paxton, S.J. (2017). A Pilot evaluation of a social media literacy intervention to reduce risk factors for eating disorders. International Journal of Eating Disorders. 50(7): 847-851.

Mingoia et al., 2019 - Mingoia, J., Hutchinson, A.D., Gleaves, D.H., Wilson, C. (2019). The impact of a social media literacy intervention on positive attitudes to tanning: A pilot study. Computers in Human Behavior. 90: 188-195.

Petranova et al., 2017 - Petranová, D., Hossová, M., Velický, P. (2017). Current development trends of media literacy in European Union countries. Communication Today. 8(1): 52.

Rasi et al., 2021 - Rasi, P., Vuojärvi, H., Rivinen, S. (2021). Promoting media literacy among older people: A systematic review. Adult Education Quarterly. 71(1): 37-54.

Rubtcova, Pavenkov, 2018 - Rubtcova, M., Pavenkov, O. (2018). The Role of Social Advertising in Solving Social Problem in Modern Society. In Psychological Science Congress-2018.

Sarwatay et al., 2021 - Sarwatay, D., Raman, U., Ramasubramanian, S. (2021). Media literacy, social connectedness, and digital citizenship in India: Mapping stakeholders on how parents and young people navigate a social world. Frontiers in Human Dynamics. 3.

Szwajca, 2015 - Szwajca, D. (2015). Determinants of the effectiveness of social advertising impact. Journal of Knowledge Society. 3(2): 1-9.

Tandoc, 2021 - Tandoc Jr, E.C., Yee, A.Z., Ong, J., Lee, J.C.B., Xu, D., Han, Z., Cayabyab, M.Y. (2021). Developing a perceived social media literacy scale: evidence from Singapore. International Journal of Communication. 15: 2484-2505.

Tikhomirova et al., 2017 - Tikhomirova, L.S., Kyrkunova, L.G., Danilevskaya, N.V., Bazhenova, E.A., Ovsiannikova, S.E. (2017). Shock advertising as a kind of social advertising. Turkish Online Journal of Design Art and Communication. Pp. 2050-2055.

Tugtekin, Koc, 2020 - Tugtekin, E.B., Koc, M. literacy, communication skills, and democratic tendency: Model development and testing. New Media \& Society. 22(10): 1922-1941.

Tully et al., 2020 - Tully, M., Vraga, E.K., Smithson, A.B. (2020). News media literacy, perceptions of bias, and interpretation of news. Journalism. 21(2): 209-226. 